\title{
New approaches for low-invasive contaminated site characterization, monitoring and modelling
}

\author{
Helen K. French • Matthias Kästner • \\ Sjoerd E. A. T. M. van der Zee
}

Received: 27 January 2014 / Accepted: 25 March 2014 / Published online: 23 April 2014

(C) Springer-Verlag Berlin Heidelberg 2014

Previously, conventional techniques for characterizing contaminated sites were often applied with limited strategic planning, resulting in time-consuming and costintensive investigation campaigns, which did not effectively support decision-making. The need for remediation, and the optimal way of doing so in terms of environmental beneficial effect and cost effectiveness, involves problem owners, the authorities, and consultants. Each of these stakeholders has to deal with lack of knowledge and broad-bands of uncertainty regarding subsurface contaminant distribution and processes. The primary cause is the spatiotemporal variability both of the subsurface, its structure and processes such as flow, transport, and biodegradation, and the pollution event. This variability leads to highly erratic patterns of

Responsible editor: Philippe Garrigues

H. K. French

Environmental Sciences, Norwegian University of Life Sciences, P.O.Box. 5003, 1432 Ås, Norway

H. K. French ( $\square)$

The Norwegian Institute for Agricultural and Environmental Research, BioforskFrederik A Dahlsv. 20, 1430, Ås, Norway

e-mail: helen.french@bioforsk.no

\section{Kästner}

Department of Environmental Biotechnology, Helmholtz-Centre for Environmental Research-UFZ, Permoserstraße 15, D-04318 Leipzig, Germany

e-mail: matthias.kaestner@ufz.de

S. E. A. T. M. van der Zee

Ecohydrology Soil Physics and Land Management, ESG,

Wageningen University, P.O.Box 47, 6700 AA Wageningen, The Netherlands

e-mail: Sjoerd.vanderZee@WUR.NL contaminant concentrations, which cannot be captured experimentally with conventional techniques that provide point measurements. An obvious solution to deal with the 'invisible subsoil' is to develop new ways of monitoring. The need for this innovation was identified by the US EPA and by the European Commission, to be based on step-by-step site characterization strategies, allowing for smart feedback loops (Fig. 1). The identified needs were laid down in a call in the FP 7 program which then acted as the starting point for the overall project approaches.

The research presented in this special issue is centred around two European Commission $7^{\text {th }}$ Framework program projects: 'ModelPROBE - Model-driven Soil Probing, Site Assessment and Evaluation' (Grant agreement No. 213161; www.modelprobe.eu ) and to a much higher extent, 'SoilCAM - Soil Contamination: Advanced Integrated Characterisation and Time Lapse Monitoring' (Grant agreement No. 212663; www.soilcam.eu ). The research activities were dedicated to both the primary development of emerging methods and, equally important, the improvement and combination of previously developed methods, interdisciplinary efforts for the investigation, and assessment of contaminated sites.

Negotiations with the European Commission started in 2008, and led to the establishment of collaboration links between the two projects selected in the competitive call for proposals within Soil Technology topic, in order to make use of the possibly synergistic approaches and to ensure the transfer of knowledge between the projects. The overlap of personnel within the partners of both consortia facilitated the collaboration. The cluster of Soil Technology Research, which is a coalition of research projects funded by the European Commission, 
Fig. 1 Dynamic work flow to select most appropriate monitoring techniques for a contaminated site

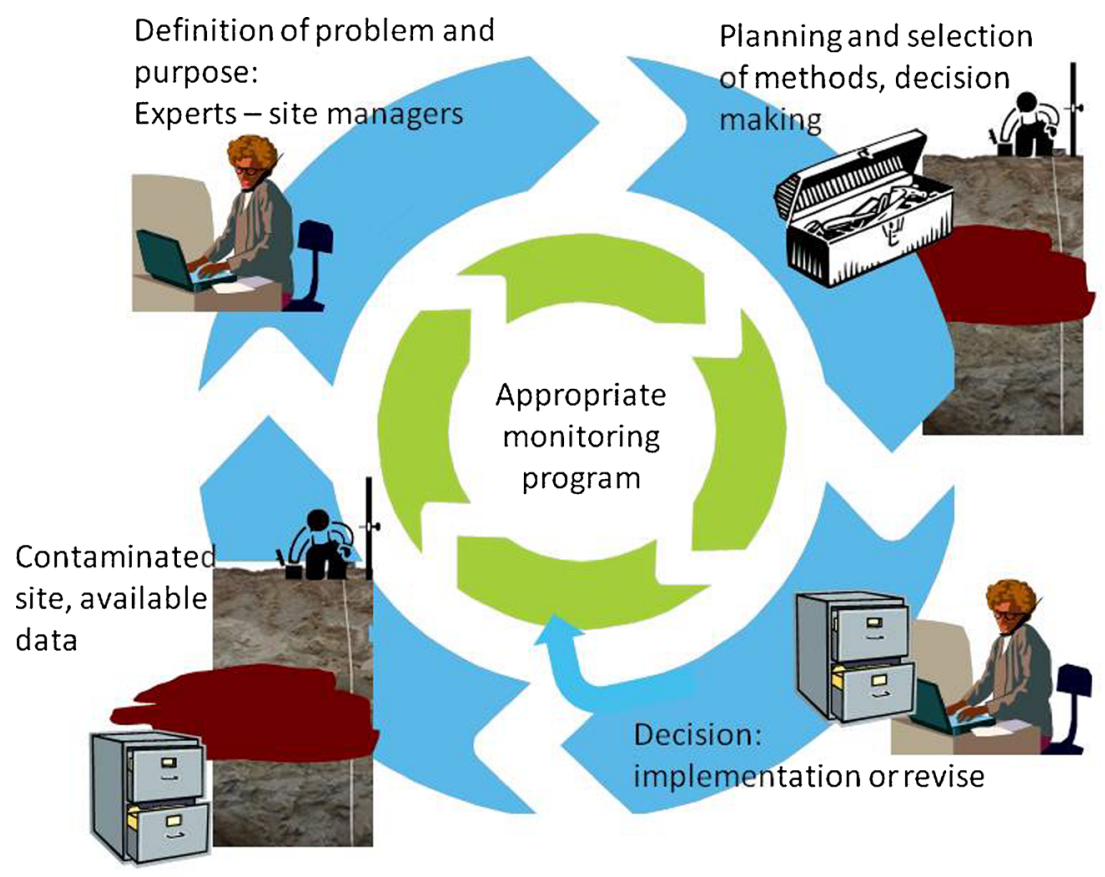

was formed mid-way in the project and an overview of these projects can be found here: http://www.ufz.de/ soiltechnologyresearch .

The SoilCAM project aimed at improving current methods for monitoring contaminant distribution and biodegradation in the subsurface. Currently, proven technology and methods that are based on invasive sampling of soil, soil water, and gaseous phase are unable to provide a sufficiently accurate database with high enough resolution as well as subsoil volume coverage, resulting in inability to assess bioremediation progress and quantification of the processes involved in such bioremediation at field sites. Two European sites were taken into consideration, i.e. the Trecate site in Italy where there was a crude oil blow out in 1994, and Oslo airport, Norway, where similar to other airports with winter maintenance, large quantities of easily degradable de-icing chemicals are supplied to the soil surface every winter. The common denominator of the two sites was their contamination by mobile degradable compounds in highly permeable subsurface. The SoilCAM project facilitated collaborative work between microbiologist, modellers, geophysicists, and geochemists. Focus on practical field situations and strong communication with stake-holders was also central. The Trecate site was used as a case study site by both the SoilCAM and the ModelPROBE projects.

One of the leading ideas of the ModelPROBE project was to evaluate the techniques against the best practise of conventional methods at fully equipped and characterized European reference sites. However, due to the large variety of methods and their specific results, this idea was recognized as being very ambitious, and finally, it turned out that the evaluation goal could only be achieved in a limited set of cases. The simple reason for this lower-than-expected outcome was that techniques which are based on different physical or biogeochemical principles cannot be directly compared in all details. Another basic idea of the project was to develop and apply integrated statistical analysis and modelling at various stages of the approach in order to extract as much information as possible from the raw data. Six years later, we can now state that the majority of the development goals have been achieved. Nevertheless, developments outside of the project also evolve, so the outcomes of several developments are punctual but no longer totally new in the field of site assessment.

In order to publish parts of the final outcome of 6 years of research, activities of the EU funded 'ModelPROBE' parts of the results are presented in this special issue and the full details of the outcomes were provided in a handbook (Kästner et al. 2012). The methods presented there are 'non- to lowinvasive', aim for cost-effectiveness, and comprise advanced geophysical site characterization techniques, new types of vegetation analysis, and improved or new biogeochemical methods, mostly combined with direct push applications. Focusing on a wide potential readership, the book contains general introduction chapters concerning the principles of site assessment combined with an overview about recent methods and detailed application manuals with an annex providing additional information of general relevance. It was published to present the outcomes understandable and available to all 
potential users: stakeholders, consultants and authorities, and, last but not least, scientists.

In this special issue, examples are given of noninvasive technology and methods, and how these can be used for a proper characterization of the contaminated subsurface, either stand-alone or in an integrated fashion using conventional monitoring and measurements combined with modelling. As in practice, the problem definition and strategy development for monitoring and characterization is ideally done in dialogue with the end-users, to ascertain compatibility between the investigation and its practical aims, French et al. (2014) address in particular this exchange of information. Next come several papers (Cassiani et al. 2014, Giampalo et al. 2014, Arato et al. 2014), in which geophysical techniques are used together with conventional approaches to characterize the subsoil in much more detail than is possible with conventional approaches alone, yet with a definite need to provide translation functions or data that relate such geophysical data to ground truth.

Besides the geophysical techniques that have become available, there are also other ones, that have as a common denominator that they leave the subsoil that is being measured or monitored intact, undisturbed. Thus, Wehrer et al. 2014 apply tomography to investigate the complexity of preferential flow and transport at the smaller scale of a lysimeter, while Bloem et al. 2014 consider a similar process with the innovative Multi Compartment Sampler MCS. Noninvasive monitoring techniques can, of course, also be extended to measurements using biota, as Algreen et al. 2014 show with their work on phytoscreening and extraction of metals by trees, and Schurig et al. 2014a for an in situ microcosm approach coupled with direct push technique for groundwater remediation assessment. The feasibility of Direct Push/Cone Penetrometer Technology (DPT/ CPT) as a function of soil type in Europe is described by Fleischer et al. 2014.

The biodegradation of mobile organic contaminants, in particular de-icing chemicals that are used at airports to remove snow and ice from runways and planes, is the focus of three papers by Toscano et al. 2014; Lissner et al. 2014, and Schotanus et al. 2014. Where Toscano et al. 2014 investigate how degradation can be enhanced, Lissner et al. 2014 investigate the biogeochemical processes, again at the relatively small scale of a lysimeter, to acquire understanding of the main processes. This understanding is used by Schotanus et al. 2014 to make essential choices with regard to their model functionality, when predicting the dependency of biodegradation on soil conditions.

The remaining papers further help improve process understanding concerning mechanisms of transport, such as the colloid retention (Dathe et al. 2014) and depending on spatial distribution of degradation potential described in Schurig et al. 2014b and Biró et al. 2014.

An important message from the work in these two projects is that every site is unique with respect to the contaminants themselves and how they behave under the natural and manmade conditions specific to the contaminated site. Therefore the methods to characterize and monitor the site should be tailored to the site specific conditions. There is still scope for improving some of the methods described with in this issue, and new methods will come in the future; therefore, policies and guidelines for handling contaminated sites should reflect ongoing developments. There is no a 'magic wand' approach to any site, and close collaboration between experts and site managers should as described in the introduction follow a step-by-step strategy, allowing for smart feedback loops.

\section{References}

Algreen M, Trapp S, Rein A (2014) Phytoscreening and phytoextraction of heavy metals at Danish polluted sites using willow and poplar trees. doi:10.1007/s11356-013-2085-Z

Arato A, Wehrer M, Biró B, Godio A (2014) Integration of geophysical and geochemical data for the characterization of biological degradation at an aged LNAPL-contaminated site. doi:10.1007/s11356-0132171-2

Biró B, Toscano G, Horváth N, Matics H, Domonkos M, Scotti R, Rao MA, Wejden B, French HK (2014) Vertical and horizontal distributions of microbial abundances and enzymatic activities in propylene-glycol affected soils. doi:10.1007/s11356-0142686-1

Bloem E, Hermon KM, de Rooij GH, Stagnitti F (2014) Spatial and temporal distribution of the leaching of surface applied tracers from an irrigated monolith of a loamy vineyard soil. doi:10.1007/s11356014-2637-x

Cassiani G, Binley A, Kemna A, Wehrer M, Orozco AF, Deiana R, Boaga J, Rossi M, Dietrich P, Werban U, Zschornack L, Godio A, Gandomi AJ, Deidda GP (2014) Non-invasive characterization of the Trecate (Italy) crude-oil contaminated site: links between contamination and geophysical signals. doi:10.1007/s11356-014-2494-7

Dathe A, Zevi Y, Gao B, Parlange JY, Steenhuis TS (2014) Functional models for colloid retention in porous media at the triple line. doi: 10 . 1007/s11356-013-2120-0

Fleischer M, van Ree D, Leven C (2014) Where can cone penetrometer technology be applied? Development of a map of Europe regarding the soil penetrability. doi:10.1007/s11356-014-2749-3

French HK, Kästner M, Van der Zee SEATM (2014) Research for investigating and managing soil contamination caused by winter maintenance in cold regions. doi:10.1007/s11356-013-2284-7

Giampalo V, Rizzo E, Titov K, Konosavsky P, Laletina D, Maineult A, Lapenna V (2014) Self-potential monitoring of a crude oil-contaminated site (Trecate, Italy). doi:10.1007/s11356-013-2159-y

Kästner M, Braeckevelt M, Doberl G, Cassiani G, Papini MP, LevenPfister C, van Ree D (2012) Model driven soil probing, site assessment and evaluation guidance on technologies. Sapienza Università Editrice, Rome, p 307 
Lissner H, Wehrer M, Jartun M, Totsche KU (2014) Degradation of deicing chemicals affects the natural redox system in airfield soils. doi:10.1007/s11356-013-2096-9

Schotanus D, Meussen JCL, Lissner J, van der Ploeg MJ, Wehrer M, Totsche KU, van der Zee SEATM (2014) Transport and degradation of propylene glycol in the vadose zone. doi:10.1007/s11356-0132033-y

Schurig C, Melo VA, Miltner A, Kästner M (2014a) Characterisation of potential for natural attenuation without groundwater monitoring wells?: a new Direct-Push probe. doi:10.1007/s11356-013-1685-y

Schurig C, Miltner A, Kästner M (2014b) Hexadecane and pristane degradation potential affected by varying conditions at the level of the aquifer - evidence from sediment incubations compared to in situ microcosms. doi:10.1007/s11356-014-2601-9

Toscano G, Colarieti ML, Anton A, Greco G, Biró B (2014) Natural and enhanced biodegradation of propylene glycol in airport soil. doi:10. 1007/s11356-013-1952-y

Wehrer M, Lissner H, Bloem E, French HK, Totsche KU (2014) Preferential breakthrough of deicing chemicals observed by electrical resistivity tomography in a lysimeter. doi:10.1007/s11356-0132252-2

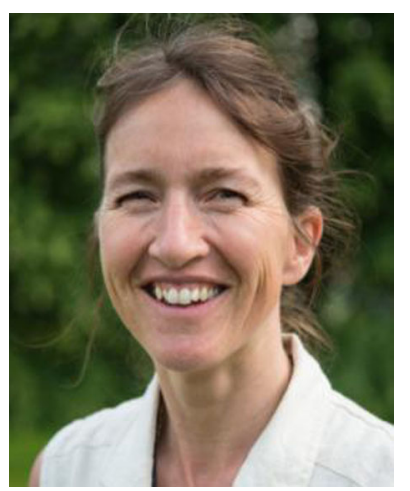

Helen K. French currently works as an Associate professor in hydrogeology at the Norwegian University of Life Sciences and as a senior research scientist at the Norwegian Institute for Agricultural and Environmental research, Bioforsk. During the last 10 years, she has coordinated several Norwegian research council funded projects with special focus on climate change, winter hydrological conditions, and consequences for infrastructures. Lately, she coordinated the EU funded SoilCAM project which involves her other main area of research, namely, how to improve methods for monitoring mobile contaminants in permeable soil and groundwater. These are also the topics of her peer-reviewed publications and reviewing work. Geophysical techniques supply a great opportunity for both mapping variability and to study flow and transport. Flow and transport modelling is required to fill in the gaps between fragmented information on geology and boundary conditions. In order to be able to predict consequences of climate change and anthropogenic activities, there is still a need to improve field methodologies and modelling tools and she enthusiastic about taking part in making such improvements!

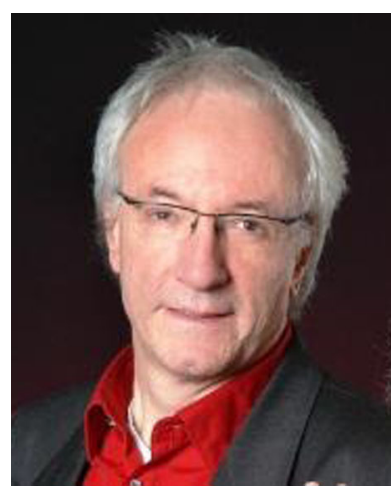

Matthias Kästner is currently head of the Department of Environmental Biotechnology of the Helmholtz-Centre for Environmental Research-UFZ and professor at the University of Leipzig. He has more than 20 years of experience in the research field of microbial degradation of organic contaminants and compound turnover at contaminated sites. His major expertise is in the field of balancing microbial transformation of organic contaminants and compounds in soil, sedi-

ments, and water environments applying isotope-labeled tracer compounds. He has recently coordinated two large EU projects, and his group is involved in several other EU and national R\&D projects as well as in projects of soil and aquifer bioremediation. He is a review panel member of European Research Council and frequent reviewer of several leading journals in the field of environmental science and has published about 120 peer reviewed articles and book chapters.

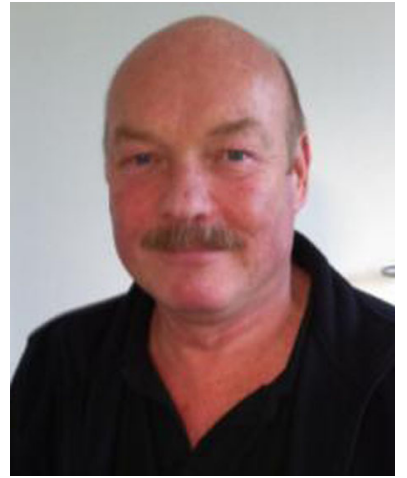

Sjoerd E.A.T.M. van der Zee is full professor in Ecohydrology at Wageningen University (Netherlands) since 2005. Before 2005, he has been a $\mathrm{PhD}$ student, associate professor, and since 1998, a full professor of Soil and Groundwater Contamination at the same university. $\mathrm{He}$ is a (co-)author to $150+$ internationally reviewed scientific articles, 30+ $\mathrm{PhD}$ studies, and numerous workshops and conferences. Main research interests are ecohydrology, stochastic modelling of flow and reactive solute transport in spatiotemporally variable soil and groundwater, soil and groundwater salinity/sodicity, density driven miscible and immiscible multiphase flow, waste water reuse in irrigated agriculture, and bioavailability of nutrients and contaminants. For a number of years, he has served as president of the Dutch Soil Science Society, research director of the graduate school SENSE (www.sense.nl) and as director of the Wageningen Institute of Environment and Climate research (WIMEK). He had different functions in scientific boards, such as the scientific advisory board of UFZ (Leipzig, Germany) and continuously coordinated or participated in EU funded projects, national science foundation, private, and government-funded research since 1988. Reviews were given of scientific papers for a broad range of journals and research proposals for different national and international agencies. 